\title{
LA ESCUELA: RELATO DE UN PROCESO DE CONSTRUCCION TEORICA*
}

Elsie Rockwell ${ }^{* *}$ Justa Ezpeleta***

\section{I. ¿Por qué construir otro objeto de conocimiento?}

Varios años de trabajo en distintos ámbitos del sistema educativo fueron creando la inquietud que origina nuestro estudio sobre la escuela primaria en México.

En cualquier nivel del sistema, los problemas que conmueven la escuela, que preocupan a los profesores, determinan el curso de su trabajo y que, en definitiva, afectan la vida de la institución y la educación que allí se imparte, son problemas difíciles de comprender desde la conceptualización más comúnmente usada para analizar la escuela y el sistema.

De esa constatación se desprende el gran tema que enmarca nuestro trabajo y que puede formularse como la construcción social de la escuela. De él se deriva la amplia pregunta inicial de la investigación: ¿qué pasa en la escuela? ¿Cómo vive, cómo se constituye permanentemente? ¿Cómo cambia y cómo sucede allí la enseñanza?

Aunque la pregunta parezca simple, está basada en diversos debates sobre los "saberes" acerca de la escuela, apoyados en otros "saberes" acerca de la sociedad.

Por una parte el análisis de las políticas educativas y de las políticas de implantación de diversas reformas nos afirmó la idea de que el sistema supone una escuela que es y no es, pero que en su concreción, verdaderamente no es. Por otra parte, dejando de lado su intención organizativa, las categorías del sistema confluyen, se corresponden, coinciden a menudo con las categorías generadas tanto por la pedagogía como por las ciencias sociales (especialmente en sus versiones jurídicas, sociológicas, antropológicas) para conceptualizar la escuela. El análisis de estas categorías, de su contenido, de sus fuentes epistemológicas, de los sectores de realidad que iluminan, fue abonando la idea, de que - si bien por explicables razones históricas - ellas se desprenden de una visión de la sociedad que la analiza desde el poder. En síntesis, encontramos dos notas relevantes: mirada desde arriba y por ello, penetración parcial de la realidad que nos interesa estudiar. No podemos extendernos aquí en la crítica sobre la frecuente o sistemática aplicación de categorías generadas para comprender el sistema, a sus unidades singulares (escuelas). La discusión sobre la pertinencia de estas categorías debe darse en la escala del sistema. No es la escala en que nos interesa trabajar. Por esta razón preferimos omitir estas categorías, pero al mismo tiempo, creemos que en su nivel son discutibles. Por su parte, la ciencia social nos ha provisto de otras categorias que son pertinentes para el estudio de la escuela singular. $Y$ estas también, a nuestro juicio, reproducen la perspectiva del poder en cuanto reconstruyen procesos que llaman "microsociales" a partir de una lógica comprometida con un orden social macro, dado, estático e incuestionable.

\footnotetext{
* Ponencia presentada en seminario CLACSO sobre educación, Sao Paulo, Brasil, junio 1983.

** Antropóloga. Investigadora del Departamento de investigaciones del Centro de Estudios Avanzados del Instituto Politécnico Nacional de México.

*** Pedagoga. Investigadora del Departamento de Investigaciones del Centro de Estudios Avanzados del Instituto Politécnico Nacional de México.
} 
Esto es claro en la tradición positivista y aun en buena parte de la tradición crítica, marxista o contestataria. Esta última, inspirada tal vez en la necesidad de construir un poder alternativo, toma con frecuencia los parámetros clásicos del positivismo, para hacer, con otro contenido, una lectura "al revés" de la misma realidad. Pero igualmente desde arriba.

Revisando conceptualizaciones y categorías fue haciéndose claro que en la reflexión sobre la escuela faltaba la idea de institución. O se la ignoraba, o se la suponía casi en términos jurídicos; nunca "la institución" aparece "construida" como objeto en la investigación que la supone.

No encontrábamos la idea de institución como expresión viva de la política estatal y al mismo tiempo como expresión viviente de la sociedad civil.

La lectura de Gramsci, Heller, y otros autores nos ayudó a identificar dos cuestiones básicas: 1) que si bien en un nivel de abstracción muy general puede hablarse de leyes de funcionamiento del modo de producción capitalista, "este se realiza sobre un mundo profundamente diverso y diferenciado". Por ello "trata de mostrar y de mutar /su/ proteiforme realidad obliga a dejar de lado cualquier pretensión de unificarlo de manera abstracta y formal y abrirse a una perspectiva micrológica y fragmentaria. En la enumeración material de lo que verdaderamente es, está... la posibilidad de aferrar la realidad histórica concreta para potenciar una práctica transformadora"1. 2) La necesidad de mirar con particular interés el movimiento social desde abajo, desde las situaciones y los sujetos que realizan anónimamente la historia y la sociedad; desde la cotidianeidad en que suceden y se construyen sus vidas, desde el lugar donde se materializa la ideología y al mismo tiempo se "refleja y anticipa" la historia. "Aceptando el paradigma marxiano de que los hombres hacen su historia bajo circunstancias determinadas, muchos marxistas acabaron por no comprender que esas circunstancias son, a su vez, vistas por los hombres de una manera "particular" y que lo que realmente importa, en la teoría y en la práctica social, es indagar esa particularidad"2

De estas grandes orientaciones teóricas, lejanas aún para la escuela, fue naciendo la idea de su construcción social. Si bien inmersa en un movimiento histórico de amplio alcance, la construcción social de cada escuela es siempre una versión local y particular de ese movimiento. Cada uno de nuestros países muestra una forma diferente de expansión de su sistema escolar público, ligada al carácter de las luchas sociales, a identificables proyectos políticos, al tipo de "modernidad" que cada uno propuso para el sistema educativo, en precisas coyunturas históricas. Las diferencias regionales, las organizaciones sociales y sindicales -incluidos los maestros y sus reivindicaciones-- las diferencias étnicas, el peso de la Iglesia, etc., marcan, en su expresión local, el origen y la vida en cada escuela. Desde allí, en esa expresión singular, se conforman internamente los frentes y las correlaciones de fuerzas, las formas de relación predominantes, las prioridades administrativas, las relievancias laborales, las tradiciones docentes, que conforman la trama real en que la educación se realiza. Una trama en permanente construcción, que articula historias locales - personales y colectivas-- entre las cuales la abstracta voluntad estatal puede ser absorbida o ignorada, engarzada o recreada, en forma particular, dejando márgenes variables para una mayor o menor posibilidad hegemónica. Una trama, en fin, que es necesario conocer porque ella constituye, simultáneamente, el punto de partida y el contenido real de nuevas alternativas tanto pedagógicas como políticas.

\footnotetext{
${ }^{1}$ José Aricó: Marx y América Latina. Alianza Editorial Mexicana, 1982 p. 241.

${ }^{2}$ José Aricó: Op. cit. p. 179.
} 
Por todo ello, la idea de construcción social de la escuela, nos impuso la necesidad de construir la escuela como "objeto de conocimiento

\section{Teoría y epistemología para una realidad no documentada}

Construir un objeto de estudio es un problema fundamentalmente teórico. No parece ocioso destacar este hecho, en un terreno como el educativo, en donde las insuficiencias explicativas o las urgencias de la acción (política y/o técnica) han generado con frecuencia alternativas, en un sentido empirista, y en otro, populista. Nuestra valoración del trabajo teórico, no deviene precisamente de un interés académico. Surge de las necesidades de la práctica y responde a una clara intencionalidad política y técnica. ¿Cómo reconocer sin teoría los espacios y las formas concretas, coyunturales, en los cuales proyectar las acciones? ¿Cómo identificar los procesos en que la intervención política y técnica tiene mayores posibilidades de tornarse fecunda? Cuestionar y transformar las concepciones y prácticas vigentes, requiere aún de mucha construcción de conocimiento.

En la teoría heredada la escuela es una institución estatal. Su pertenencia legal al Estado, la transforma automáticamente en vocera, o representante unívoca de la voluntad estatal. Tiene una historia documentada que da cuenta de su existencia homogénea y homogeneizante, como unidad de un sistema. Es difusora de valores universales -e inobjetables - que en cada escuela se transmiten en su pureza. Así, en la versión positivista; la escuela además de lograr por la vía de la socialización, la internalización de "valores y normas comunes a la sociedad", logra también la concreción de los derechos cívicos y de la justicia social. Algunas versiones críticas por su parte, basándose en la misma historia documentada de la escuela, demuestran, sobre la misma información, su carácter reproductor de las relaciones sociales de producción.

Sin embargo, con esa historia y esa existencia documentada de la escuela, coexiste otra historia y otra existencia no documentada a través de la cual toma forma material, toma vida. Es la historia de los sectores de la sociedad civil, que a través de sus trabajadores, sus alumnos y los padres, se apropian de los apoyos y prescripciones estatales y construyen la escuela.

Por ello, aquella versión documentada, oficial o académica, es parcial y produce un efecto ocultador del movimiento real. Esa tradición por ejemplo nos ha enseñado a ver en la escuela, dentro de ella, lo pedagógico y fuera de ella -en las causas, efectos o resultados de la escolaridad- lo político. Por su parte los análisis críticos reproduccionistas, en particular- incorporan la "transmisión ideológica" al juego pedagógico, pero siguen sin darle lugar a "lo político" dentro de la escuela.

El conocimiento de la vida de la escuela en sus formas concretas, cotidianas y la integración en ella de la acción de los sujetos particulares, evitando la abstracción formal, es uno de nuestros principales problemas teóricos. ¿Cómo integrar en la teoría el carácter inevitablemente heterogéneo de lo cotidiano? ¿Cómo construir categorías que liguen la historicidad de lo cotidiano a la historia del movimiento social?

Estas y otras preguntas remiten a buscar la pertinencia del referente empírico y las opciones metodológicas para los problemas definidos. Es decir, conducen a la reflexión epistemológica que necesariamente acompaña a la construcción teórica.

Diversas formas de racionalismo han advertido el peligro de "perderse" en la variedad y heterogeneidad infinita de lo particular, de lo cotidiano, de lo coyuntural; con ello tienden a 
condenar al campo de lo "no-investigable" a una buena parte de la realidad social, justamente a esa parte que coincide con lo no-documentado.

El intento de conocer estas realidades suele calificarse de "empirismo" e "historicismo" desde perspectivas racionalistas que dicotomizan lo real en esencia - apariencia, estructura - acontecimiento, orden-azar.

Históricamente, sin embargo, las fronteras precisas de las divisiones dicotómicas de la realidad, en conocible - no conocible, se han modificado junto con el proceso de construcción teórica. Aún en la ciencia social paradigmática, la lingüística, tal dicotomía (lengua-habla) ha cedido frente a la rica elaboración de conceptos que apresan otros niveles y contenidos de los procesos de comunicación y de significación.

La revaloración del conocimiento histórico, y del análisis coyuntural, la integración del análisis de las particularidades nacionales en la determinación del movimiento político, etc., son otras señales, confluyentes, de la paulatina incorporación consciente de lo noconocible a la reflexión teórica ${ }^{3}$.

Ha sido constante en este trabajo la búsqueda, la explicitación, la profundización de relaciones particulares e imprevistas. Lo paradójico ha sido que la observación y el análisis de esos episodios cotidianos e inconsecuentes de los que fuimos testigos, permitió elaborar y enriquecer categorías, precisar conceptos y construir descripciones analíticas. El análisis de una situación particular, con todo el aporte de conocimiento antecedente, da la posibilidad de armarse de conceptos que permitan discernir en otras situaciones, los sentidos de las acciones emprendidas desde diferentes puntos del juego social y político.

\section{El encuentro con el Estado y lo otro en la escuela}

En nuestra experiencia, la construcción como proceso y la construcción corno producto están inextrincablemente unidos. Tal vez por eso hemos optado por mostrar en lo posible su imbricación. Observación y análisis, dentro de la tradición investigativa en la que, después de mucho reajuste de cuentas, nos inscribimos ${ }^{4}$, caminan interconectadamente con la reflexión y construcción teórica, dan lugar a debate teórico y fundamentan nuevas concepciones. El recuento de este proceso intenta mostrar las limitaciones de las categorías heredadas para ver la escuela, y la necesaria búsqueda de otras concepciones 5 .

\footnotetext{
${ }^{3}$ Encontramos construcciones análogas, que nos han ayudado en nuestro trabajo, en áreas temáticas, generalmente alejadas de la nuestra. Historias culturales y del saber popular por ejemplo, construidas al margen de los paradigmas de "la razón". Recordamos, en especial los trabajos de Carlos Monsivais sobre la cultura urbana en México; la obra de Carlos Guinzburg, en particular su libro, $E l$ queso y los gusanos; el trabajo de P. Thomson sobre formación de la clase obrera, entre otros, y la importante reflexión colectiva sobre la búsqueda de nuevos modos del conocimiento a cargo de Aldo Garganti, Crisis de la razón. (Siglo XXI, 1983).

Asimismo, la relectura de clásicos marxistas (orientada por trabajos de Aricó, Portantiero y otros) que han guiado la búsqueda para pensar en y para la realidad de América Latina, jugó un papel preponderante para comprender la importancia de la construcción histórica y el estudio de lo particular.

${ }^{4}$ Se trata de la tradición etnográfica, cuya esencia identificamos como "documentar la realidad no documentada". Hemos analizado y discutido sus posibilidades para la captación de lo cotidiano y creemos haber convertido su perspectiva colonial, apropiándonos de sus instrumentos para "mirar desde abajo". Esta tradición investigativa cuando no se asume con pretendido ateoricismo, o dentro de su vertiente empirista, permite integrar al proceso investigativo el necesario desarrollo conceptual. Ver E. Rockwell, "Etnografía y teoría en la investigación educativa", Documento Mimeo DIE, 1980.

${ }^{5}$ Resulta difícil relatar el proceso sin incorporar los numerosos referentes concretos que tenemos presentes al afirmar nuestras propuestas. Sólo la falta de tiempo y espacio explica esta ausencia de mención al material de campo.
} 
Llegar a las escuelas a observar, a registrar lo que se observa, supone para el investigador múltiples tensiones. Aun cuando la preparación previa ha puesta) en duda los preconceptos y están claros los problemas teóricos que enmarcan nuestra búsqueda, se impone, de todos modos una permanente vigilancia tanto psicológica como epistemológica.

De nuestras amplias preguntas iniciales, se desprende también una amplia e inquietante consigna para el registro de la información de campo: registrar "todo" lo que se vea. No es sencillo. Sabíamos que registrar "todo" no es posible, pero proponíamos con ello ampliar el margen de nuestra mirada, agrandar los límites de la selectividad. Se trataba de desafiar a la atención sabiendo que ella no es autónoma. Teníamos conciencia de que las situaciones mas atendibles" para el observador son aquellas que para él pueden cargarse de una significación inmediata y al mismo tiempo, que este tipo de significaciones podía operar como interferencia para obtener la información que buscábamos. Lograr registros en los que se asiente por igual lo significativo y lo no evidentemente significativo implicó todo un aprendizaje y este ha sido uno de los puntos de permanente vigilancia en el trabajo de campo.

Pero ¿qué es lo aparentemente significativo que se impone como "lo mas visible"? En la reflexión consciente sobre este proceso encontramos que la observación inicial se orientaba por diversas, nociones del "sentido común" sobre la escuela; por las conceptualizaciones pedagógicas y sociológicas recibidas y por el ordenamiento formal del sistema escolar, expresada en categorías que muestran una estrecha relación con aquellas conceptualizaciones.

Para el sentido común, la escuela es el dominio de lo esencialmente bueno y valioso. Con mayor sofisticación la pedagogía ofrece conclusiones parecidas. Sentido común y pedagogía alimentan sistemáticamente una actitud valorativa para mirar la escuela. A pesar de las precauciones, todo esto se pone en juego cuando uno llega a observar una escuela. Y allí comienza el asalto de las expectativas: se espera un cierto orden, una cierta disciplina, alguna regularidad en las acciones; se tienen parámetros -los más diversos - para identificar, en diagnóstico rápido, al "buen maestro", al "alumno terrible". El observador se sorprende cuando se enfrenta a situaciones inexplicables por sí mismas, sin relación posible con lo que se "espera" que suceda. La alta frecuencia y diversidad de estas situaciones ayuda a convencerlo de que sabemos muy poco sobre la vida de la escuela.

El impulso por comprender al observar agrega al sentido común las categorías de la ciencia social y las del propio sistema educativo. Se apela a la idea de "institución" para encontrar parámetros y pautas y aparece la tentación de localizar roles, jerarquías, normas, funciones, etc., que el conocimiento previo permite anticipar. También aquí golpea el desconcierto: roles, normas, jerarquías, están y no están, se vislumbran y se pierden en relaciones o situaciones inapresables en esas categorías. Nuevamente el fracaso de la significación inmediata, nuevamente la convicción de que hay que ampliar la mirada y desconfiar de las categorías heredadas. Un trabajo permanente de análisis de registros, de ida y vuelta entre datos de campo y esfuerzo comprensivo, sustenta el avance progresivo para superar los sentidos "evidentes" de las situaciones. El análisis sostenido permite identificar y relacionar indicios y desde allí orientar las nuevas observaciones. En ocasiones esas pistas se diluyen a poco de seguirlas, pero a menudo cada una de ellas abre encadenamientos que nos conducen a la trama que queremos reconstruir. Cuando todo lo "no significativo" se transforma en indicio, en pista posible de 
eso que buscamos, los registros comienzan a documentar con mayor precisión la aparente dispersión de la vida escolar.

La reiterada búsqueda de recurrencias, la confrontación de versiones alternativas, la atención a eventos que, aunque esporádicos, revelan regularidades y conflictos poco visibles en la rutina diaria, amplían nuestra capacidad de ver y prever lo que ocurre en la escuela. Este proceso analítico pone en juego el debate teórico y la "vigilancia" epistemológica.

Creíamos, al comienzo del trabajo, y aún lo creemos, a veces, que estudiaríamos la "institución escuela". Hoy, el término y el concepto "institución" nos resultan estrechos y nos enfrentan a la necesidad de reconceptualizar o de inventar un término que de cuenta de este sector de lo real que aún no terminamos de construir.

Estudiar la escuela en su expresión cotidiana, en su existir de todos los días, implica una opción por "mirar desde abajo" que no ha sido muy frecuente en las ciencias sociales $^{6}$. A menudo pensamos que el desarrollo de estas ciencias como brazo intelectual del naciente orden burgués, marcó indeleblemente sus maneras de mirar la realidad. La preocupación positivista por comprender el nuevo "orden" de la sociedad, por implantar y conservar un nuevo equilibrio y la consecuente necesidad de detección de los puntos de "negación" (anomia, desviación, etc.) están presentes en las categorías que heredamos de la ciencia social. Ellas permiten reconstrucciones "coherentes"; para una mirada desde el poder, la dinámica del "orden" social es siempre expresión de alguna "racionalidad".

El positivismo inauguró también otra historia, la de los hechos progresivos, la que borró la memoria social. Impuso el presente como la dimensión del tiempo, implantó el futuro como la medida del progreso, recobró sólo "lo institucional" o "instituido" del pasado e ignoró - tal vez por irracional- la memoria colectiva y la historia viva que hacen los pueblos. Tiempo y espacio del poder congelaron esta historia. La atemporalidad, la ahistoricidad de las categorías heredadas de esa ciencia, no resultan azarosas si pensamos en sus orígenes. Si tenemos en cuenta aquella confluencia entre saber y poder es más fácil explicarse la frecuente superposición entre las categorías de la ciencia social y las propias de la burocracia escolar.

Los conceptos clásicos acerca de "institución" y específicamente de institución educativa, ponen énfasis en los fines y objetivos institucionales y la organización jerárquica, en la legalidad y normatividad reglamentaria como determinantes del comportamiento de los actores que cumplen ciertos roles y como referentes para el control y la evaluación; estos conceptos son el trasfondo implícito común tanto de la planeación educativa como de gran número de investigaciones educativas que no encuentran dificultad alguna en convertir la clasificación oficial de escuelas, maestros y alumnos en sus marcos de muestreo o en tomar como "datos" la información que el sistema recoge con sus propios mecanismos y categorías; en aceptar como parámetros de evaluación los que el sistema propone. La continuidad entre el ámbito investigativo y burocrático se moderniza con modalidades de "análisis de sistemas" y "prospectiva", sin que se cuestione la estructura básica de su concepción de la escuela.

\footnotetext{
${ }^{6}$ Desde luego, existen numerosos estudios que recortan un pequeño ámbito "de abajo" de las instituciones educativas, como son los de socialización, interacción maestro-alumnos, micro-etnografía, etc. Sin embargo, focalizan en procesos que se dan en esta escala y generalmente no los ligan Con el contexto institucional, no "miran desde abajo" a la escuela.
} 
Cuando aparecen estas categorías científicas y administrativas en el proceso de observar o analizar lo que ocurre diariamente en las escuelas, es en momentos precisos, como reflejos estáticos de ese movimiento permanente que es la escuela. Ellas se encuentran fuertemente ligadas a la lengua escrita. En los frecuentes pedidos de documentación que el sistema hace al director y maestro, esas categorías apresan de manera empobrecida el flujo escolar; los datos se "ajustan" a las exigencias del formato, sin que las contradicciones preocupen mayormente a quienes rinden sus informes. Aparece de nuevo en las entrevistas iniciales con los directores, en el discurso más formal de los maestros que suponen que nuestro interés en saber algo de la escuela se guía por las mismas preguntas.

Sin embargo, su papel regulador hace que estas categorías sean significativas en la escuela; la calificación y reprobación de alumnos, la apelación al programa para legitimar el quehacer docente, al calendario oficial para defender el descanso, al reglamento de padres para lograr colaboraciones, inciden en lo escolar. Las categorías organizativas y normativas se ven, es-tan en juego, en la escuela; pero la vida escolar no puede verse, o abarcar-se toda, desde ellas. Su abstracción y su parcialidad son medida precisa de los límites de aquel "conocimiento" que el sistema escolar genera, desde arriba, de su propia realidad.

Al intentar delimitar, para orientar la observación, a la "unidad" escuela, desaparece progresivamente el referente del "sistema" escolar. Los límites administrativos y sociológicos de cada escuela se tornan difusos —en este nivel de la existencia diariaporque "lo social" y "lo político" circundante la impregnan y también la constituyen. Es imposible explorar, por ejemplo, las formas de negociar la imprescindible ayuda de los padres en el mantenimiento de la escuela, sin tocar el sustrato de organización social y política local. En este caso, no nos son útiles las categorías tópicas de la sociología para "focalizar" la observación, justamente porque sólo es posible deslindar la escuela de su entorno social después de un arduo proceso analítico.

En el lado contrario, es análogo el problema de observar y reconstruir las formas y fuerzas precisas que despliega el Estado en la escuela. Presente en formas que no anuncia en su discurso, como las políticas; ausente justo en aquellos momentos, como en la enseñanza, donde proclama unificación y control, el Estado se muestra y se oculta en la escuela. Es posible sin embargo ir construyendo maneras de verlo que no coincidan con las auto-imágenes que difunde.

Desde la escuela, comprendida inicialmente dentro de su espacio físico, fue ineludible explorar "hacia arriba", hacia las instancias cuya designación jerárquica asegura su ascendencia y poder sobre los maestros de base. La supervisión administrativa, la orientación técnica, la gestión sindical oficial ${ }^{7}$, tienen caras sólo visibles desde su incidencia en la escuela que nos importa conocer. Se abre un mundo de caminos burocráticos (no sin sus puntos de amenaza o coerción) que maestros y padres deben transitar para poder asegurar la continuidad —la vida misma— de la escuela.

Es cierto que, en una medida mínima pero bien calculada frente al costo social y político de no hacerlo, este Estado ofrece la educación primaria a toda la población infantil. Para ello, mantiene como trabajadores asalariados a los maestros, financia en parte el local escolar y manda textos únicos, gratuitos, a todos los niños. Certifica, sin mayor

\footnotetext{
${ }^{7}$ En México, la agrupación sindical de los maestros (SNTE) es controlada con mayor o menor coincidencia coyuntural, por el Estado; la disidencia, por su parte, es incipiente y sistemáticamente perseguida.
} 
preocupación por el control, el aprendizaje logrado en seis años de escolarización. Estos elementos materiales son garantía de una matriz común a las escuelas de todo el país; normas, prescripciones, libros, documentos y organización formal únicos, reticulan la propuesta uniforme de la educación estatal. Sobre este fondo el propio Estado genera acciones diferenciales de zona a zona, de escuela a escuela, que pueden reducir la demanda efectiva, institucionalizar la deserción temprana, discriminar a ciertos subsistemas en cuanto al apoyo material, "adaptarse" según su concepción del "medio" o de acuerdo con su estimación de la participación comunitaria y privada, para relativizar su propia obligación constitucional de proveer educación básica, laica, universal, gratuita. Filtrado a través de todo ello, se encuentra como constante implícita, la presencia política del Estado en la escuela.

Encontramos también aquí, en la mirada desde abajo hacia la burocracia estatal, que las categorías oficiales, la documentación accesible, remiten a puntos precisos pero a veces inocuos. Lo que ocurre fuera de los límites de los reglamentos, fuera de clase, fuera de asamblea, fuera de visita rutinaria del supervisor, indica los reales asuntos en juego, los contenidos ocultos de los ordenamientos y procedimientos administrativos y técnicos. La fuerza de las categorías "naturales" que ubican, desagregan o jerarquizan al magisterio, tienen un trasfondo coercitivo ejercido sobre sus intereses personales y profesionales, que tiende a asegurar el control político, más que regular la "racionalidad" del trabajo.

No quisiéramos dejar la impresión de que es posible una demarcación precisa entre lo estatal y lo civil en la escuela. La presencia y la acción estatal efectiva en la construcción de la escuela va sedimentándose. La superposición de estilo y distribución reglamentarios de construcción escolar, así como de programas y contenidos de enseñanza, o las sucesivas banderas y 'aperturas' sindicales posibles en diferentes épocas, también encuentran lugar en la memoria colectiva, en la constitución efectiva de la escuela. Esto significa que lo que el Estado introdujo o apoyó en coyunturas pasadas, puede en la actualidad adquirir el sentido de resistencia callada frente a la modernización irreversible propuesta por el propio Estado. Sólo al historizar la conformación del Estado, al complejizar el concepto mismo ${ }^{8}$, suponemos posible captar el sentido de su presencia actual en las escuelas. Y simultáneamente suponemos poder conocer la incidencia de todo lo otro que también es constitutivo de la escuela; todo aquello que desde su visión normativa o categorial al Estado califica de "desviación", de acción "negativa".

\section{Conceptos para apresar lo cotidiano en la escuela}

En nuestra construcción para integrar eso "otro" de la escuela, nos hemos apoyado en algunos conceptos.

Uno de los anclajes iniciales fue la noción de "vida cotidiana ", que fundamentó la opción metodológica y el recorte empírico. Poco a poco se convirtió en herramienta conceptual importante para el análisis, En efecto, aproximarse a la escuela con la idea de "vida cotidiana" significa más que "ir a observar" lo que ocurre ahí diariamente; orienta cierta búsqueda y cierta interpretación de lo que en la escuela se puede observar.

Como concepto, "lo cotidiano" fue formulado sólo después de cuestionar acepciones comunes del término, que lo refieren a la vida de sectores anónimos, de baja jerarquía

\footnotetext{
${ }^{8}$ Esto requiere comprender su conformación específica en cada contexto histórico, su base de alianza entre sectores dominantes y subalternos, su garantía de condiciones mínimas de producción, su participación en la construcción y destrucción de las relaciones de la sociedad civil.
} 
social y "nula participación histórica"; por oposición lo no-cotidiano suele identificarse con la Historia, es decir, con aquello que desde el poder se supone significativo para el movimiento histórico. Empezamos a reconocer en cambio, que en todos lados hay vida cotidiana, que nuestro propio proceso investigativo se puede ver también bajo ese aspecto, que es posible reconstruir lo que ocurre cotidianamente en cualquier "lugar" de la realidad social, aun en los lugares privilegiados por las visiones jerárquicas y legitimadoras del poder: ("El ámbito cotidiano del rey es la corte, no el reino").

El concepto de "vida cotidiana" delimita y a la vez recupera conjuntos de actividades, característicamente heterogéneos, emprendidos y articulados por sujetos particulares. Las actividades observadas en una escuela, o en cualquier contexto, pueden ser comprendidas corno "cotidianas" sólo con referencia a esos sujetos; así, se circunscriben a "pequeños mundos" cuyos horizontes se definen diferencialmente, de acuerdo con la experiencia directa y la historia de vida, de cada sujeto. Como categoría analítica lo cotidiano se distingue de lo no cotidiano en un mismo plano de la realidad concreta; lo que es cotidiano para una persona, no es siempre cotidiano para otros. En un mundo de diversidad, como el escolar, se empiezan a distinguir así las múltiples realidades que se pueden identificar como "escuela" por determinados sujetos, a comprender que la escuela es objetivamente distinta según el lugar donde se la vive.

El recorte de lo cotidiano, para el cual el sujeto particular es el referente significativo, define un primer nivel analítico posible de las actividades observables en cualquier contexto social. Para el investigador, este conjunto de actividades cotidianas es, y debe ser, articulable desde muchos otros niveles analíticos. Las continuidades y discontinuidades entre las actividades (es decir, su desarrollo histórico, su vinculación o consecuencia en relación con procesos sociales) se perciben al determinar unidades y categorías analíticas que atraviesan y rebasan los límites que lo cotidiano define para cada sujeto.

En ese sentido es claro que la realidad escolar no es idéntica a la experiencia directa que determinados sujetos (incluyendo a los que investigan) tienen de ella, y su reconstrucción requiere la integración de varios niveles de análisis. No nos proponemos por lo tanto identificar nuestro objeto de conocimiento con el "conocimiento cotidiano" de la escuela. No nos interesa conocer en forma individual las múltiples vivencias de la escuela. Al integrar lo cotidiano como un nivel analítico de lo escolar, consideramos poder acercarnos de modo general a las formas de existencia material de la escuela y relevar, el ámbito preciso en que los sujetos particulares involucrados en la educación experimentan, reproducen, conocen y transforman la realidad escolar.

En el proceso de observación algunos sujetos particulares (tal maestro o director, la familia conocida, el grupo de alumnos que se acercan) cobran una importancia poco común en investigaciones sociales. Cada vuelta a la escuela aporta nuevos indicios para comprender desde estos sujetos la "lógica" de ciertas actividades observadas en la escuela, y reconstruir redes que los unen a otros sujetos. Esta búsqueda adquiere en ocasiones la fascinación del chisme o el suspenso de la novela policial. $Y$ a pesar de reiterado seguimiento de determinados sujetos, o más bien por ello, se procede paralelamente a establecer, mediante la abstracción, ciertas relaciones de valor analítico más amplio. En las descripciones finales, estos sujetos permanecen anónimos; lo que se constituye a partir de ellos se reconoce y se constata de nuevo en otros ámbitos.

Corresponde a este proceso analítico cierta conceptualización de sujeto, que conviene distinguir de otros usos del término. Empleamos sujeto en un sentido distinto al sujeto 
biológico y psicológico, que tiende a reconstruirse por abstracción de estructuras o funciones compartidas por el género humano. Como sujeto social, intentamos por otra parte, no sustituirlo por las variables de ubicación social, por los mecanismos de socialización y de interpelación ideológica que lo "determinan". Entre estos dos polos, parece posible definir a un sujeto, conocible a través del "conjunto de relaciones sociales" que conforma su "pequeño mundo" y que lo une a integraciones ${ }^{9}$ de diverso orden. Se concibe como sujeto "concreto", no por tratarse de un "individuo", sino por el carácter histórico y específico de aquellas relaciones.. Al vivir su vida, al realizar su trabajo, este sujeto emprende diversas actividades para poder reproducirse en el modo histórico particular del mundo en que vive, pero esas actividades son a la vez constitutivas de este mundo. Las actividades de los sujetos particulares, circunscritas a "pequeños mundos", importan siempre en alguna escala. Se inscriben a la vez en diferentes niveles de integración.

En la escala de integraciones mayores sus actividades importan a través de procesos como el de formación de clases (o aun de "bloques históricos") es decir, de constitución de sujetos colectivos potencialmente transformadores de las relaciones hegemónicas.

Si bien el movimiento social se hace más evidente al analizar las integraciones sociales de mayor escala, las discontinuidades, al interior de cada integración, son apreciables justamente en las sucesivas articulaciones o engarces entre los pequeños mundos en que se desenvuelve la actividad humana. Una de las formas que ocultan el movimiento real de la sociedad, es la distancia entre las concepciones, ordenadas y coherentes, que describen a las integraciones mayores y el sentido de las prácticas reales en los ámbitos que las constituyen. Por ello, también llegan a ser explicativos del movimiento social, los procesos presentes en las prácticas y los saberes reales de los numerosos "pequeños mundos" que forman cada integración. El análisis de lo cotidiano en la escuela apunta a ese nivel explicativo de la realidad.

La escuela, tomada como unidad singular del sistema escolar, es un primer nivel de integración. Ha sido un dilema trasladar a este nivel el concepto de vida cotidiana y de sujeto como su centro. De hecho, al reconstruir lo escolar, recortamos analíticamente la totalidad de vida del sujeto, ya que desde éste (desde el niño que también es alumno, desde la mujer que también es maestra) se organizan y se jerarquizan con diferentes grados de delimitación, congruencia y conflicto las numerosas actividades y ámbitos de su "pequeño mundo". Las actividades cotidianas no siempre se reparten en dominios aislados. De hecho, puede haber continuidad entre actividades cotidianas diversas que realiza un sujeto particular en distintos ámbitos: puede haber también enormes diferencias entre las prácticas que caracterizan a los distintos ámbitos de una misma integración, como la escolar. Así, el saber que muestra un maestro en el salón, frecuentemente incorpora elementos de otros dominios de su vida cotidiana; expresa a la vez una distancia frente a los componentes "didácticos" que son "cotidianos" en las instancias de formación docente de la propia investigación escolar.

Circunscribimos vida cotidiana y sujeto a la escuela; sin embargo, no lo hacemos por medio de la concepción oficial de la escuela, de las categorías que definen lo que legítimamente pertenece a su ámbito institucional (la enseñanza y la disciplina sí, la política no, por ejemplo). Dejamos abierta la delimitación de la escuela para reconstruir a partir de "todo" tipo de cosa que sucede en, desde, alrededor de y a pesar de la escuela, lo que puede ser constitutivo histórico de la realidad escolar. Reconstruimos lo que puede

\footnotetext{
${ }^{9}$ Usamos "integración" como término general para cubrir varios niveles de unidades de análisis social (familia, comunidad, partido, nación, etc.) según el uso de A. Heller, Sociología de la vida cotidiana, Península, 1973.
} 
ser común, lo que puede ser divergente o contradictorio, en las diversas formas reales de vivir la escuela. Se encuentra un espacio de intersección entre sujetos particulares que aportan sus saberes específicos a la constitución de una escuela; en este, se incorporan y devienen significativos, numerosos elementos no previstos en las categorías heredadas de lo escolar. La realidad escolar aparece más bien mediada por la actividad cotidiana la apropiación, la elaboración, la refuncionalización, el rechazo- de sujetos particulares, y en ciertos momentos, de sujetos colectivos.

La heterogeneidad es uno de los caracteres más destacables en la vida cotidiana en general. La escuela no escapa a esta regla, no sólo porque existe una gran diversidad de ámbitos, de sujetos, de escuelas, sino sobre todo porque en cada conjunto de actividades, en cada "pequeño mundo", coexisten elementos con sentidos divergentes. Cualquier registro de actividades cotidianas escolares muestra incongruencias, saberes y prácticas contradictorias, acciones aparentemente inconsecuentes. Al integrar conceptualmente "lo cotidiano" al objeto de estudio, intentamos conservar ese aspecto heterogéneo y no perderlo al definir tipologías discretas y estructuras coherentes.

La única forma de dar cuenta de lo heterogéneo, de no perderlo, pero tampoco perderse en él, es reconocer su carácter de construcción histórica, analizar desde el conocimiento de su origen y ordenamiento histórico, el sentido de las actividades que se reproducen en la actualidad.

Al establecer su carácter histórico, es posible comprender que el contenido social del conjunto de actividades cotidianas no es arbitrario; no responde a una elección que hace cada sujeto frente a una gama infinita de posibilidades. Las actividades particulares contribuyen a procesos específicos de producción y reproducción social, es decir: conforman "mundos" que para otros sujetos son los "mundos dados"; recuperan y redefinen instituciones construidas con anterioridad; producen valores que se integran al movimiento social; confluyen en procesos políticos de signo progresivo y regresivo. En todos estos procesos, las actividades cotidianas "reflejan y anticipan" la historia social.

Lo heterogéneo no es lo infinitamente variable, no es lo determinado voluntariamente en cada caso individual. En la escuela, la interacción de procesos constitutivos a diferente escala (salón, escuela, sistema) asegura la continuidad relativa" de diferentes categorías sociales que ordenan la actividad escolar, de escuela a escuela, de momento a momento en la trayectoria de cada escuela. Algunas de las actividades más persistentes caracterizan a la práctica docente del siglo pasado; el traslado de directores de una escuela a otra muestra la continuidad básica del conocimiento del oficio, frente a las formas generadas en cada escuela particular. Al analizar las recurrencias, al reconstruir las diferentes "lógicas" en juego en la negociación del destino de una escuela, identificamos las categorías sociales organizativas que sustentan o bien resisten la conformación estatal de lo escolar, que expresan las diferentes corrientes de su constitución histórica.

\section{Procesos para vincular la vida cotidiana y la historia.}

Cuando planteamos, como ejes principales del análisis procesos constitutivos de la realidad escolar, es evidente que priorizamos una opción de construcción del objeto sobre otras posibles (sistémicos, estructurales, evaluativos, funcionales, comparativos, etc.). No hay nada nuevo en plantear como intención investigativa la reconstrucci5n de procesos; de hecho, el "proceso de enseñanza-aprendizaje" ha sido consagrado ya como objeto de estudio central a la escuela, (aunque dudamos frente a la evidencia del salón de clase, que se trate en realidad de "un" proceso y no dos). 
Fue importante, por lo tanto, aclaramos lo que entendíamos por "proceso". La primera precaución necesaria nos remitía a la escala de pertinencia de los conceptos seleccionados. Como proceso, la enseñanza es analizable únicamente en la escala de la práctica cotidiana del docente; la estratificación social ligada a la escolarización diferencial, en cambio, es apreciable sólo en la escala del "sistema" escolar en su conjunto. Al evaluar diversos conceptos que denotan procesos ha sido necesario cuidar su definición precisa, su elaboración categórica en relación con "lo observable" y su jerarquía en interacción con otros procesos, para adecuarlos a la escala "cotidiana" que optamos por estudiar.

Un concepto que presentó problemas en este sentido es el de la reproducción, asociada a la concepción de escuela como aparato ideológico de Estado. Es cierto que una lectura "reproduccionista" de la vida cotidiana de las escuelas que observamos es posible y aun convincente, dada la presencia de las ideologías impuestas por el Estado capitalista, de las prácticas enajenantes análogas a las de la fábrica, de la reafirmación del pretendido valor universal de la educación sobre toda evidencia contraria. Sin embargo, si no se es selectivo en la observación, en la escala de los ámbitos cotidianos por lo menos, el proceso de reproducción es insuficiente para dar cuenta de "todo" lo que sucede. La heterogeneidad y particularidad de lo cotidiano exigen otras dimensiones ordenadoras; imponen con fuerza el reconocimiento de sujetos que incorporan y objetivan a su manera, prácticas y saberes de los cuales se apropiaron en diferentes momentos y contextos de vida, y que contienen historia acumulada por siglos. Consideramos que esta exigencia de historizar el proceso de reproducción, aunque se hace evidente en la escala cotidiana, no es menos significativa a una escala mayor, en que la constitución social de la institución escolar responde a movimientos distintos en cada contexto histórico.

Al tomar en cuenta como referencia constante la historia, también empezamos a distinguir entre los procesos pertinentes a esa referencia y otro tipo de procesos considerados dentro de marcos de referencia más sistémicos o sincrónicos, propios de los paradigmas dominantes. Estos tienden a manifestar un carácter "neutral" frente a las luchas sociales y los movimientos políticos que conforman y rearticulan la organización de la sociedad civil. En las concepciones heredadas de institución, los procesos privilegiados tienen ese sentido; por ejemplo, se considera que el funcionamiento y la permanencia de cualquier institución se asegura durante generaciones, "a pesar de" los individuos, por procesos efectivos de internalización de normas y de socialización en pautas de comportamiento uniformes. En los análisis sistémicos, se prioriza como proceso a la "comunicación", o "transmisión de información", sin importar lo comunicado.

Estos conceptos son ahistóricos en un sentido específico: no captan procesos en los que "están en juego" propuestas alternativas de construcción o conocimiento de lo social; indican aquello que, vaciado de contenido, resulta "común" a los diversos momentos de lo social. En nuestra búsqueda y definición de procesos, interesa resaltar el sentido (en ambos sentidos de la palabra) histórico del movimiento, su constitución y consecuencia diferencial según el tiempo o el lugar específico. Por ello, descartamos la posibilidad de establecer y denominar "funciones" de la escuela como institución; en su lugar hemos intentado identificar una serie de procesos sociales, no exclusivos de la educación que se dan en cada escuela en proporciones y de maneras distintas.

La reflexión sobre uno de los procesos que ha resultado clave en el análisis, el de apropiación (según el desarrollo específico que A. Heller realiza del concepto), puede ejemplificar lo anterior. Como uno de los procesos básicos que vinculan el sujeto particular a su mundo cotidiano, y a otras integraciones de mayor escala, la apropiación subyace al 
conjunto de prácticas y saberes que observamos. A diferencia del concepto de socialización, que supone una acción homogénea de la sociedad sobre el individuo, con la resultante internalización de normas de existencia a priori, la "apropiación" nos permite dar cuenta de una acción recíproca entre sujetos individuales o colectivos y diversas instituciones o integraciones sociales.

En cada ámbito institucional, y de manera continua, son determinados sujetos los que se apropian diferencialmente de las cosas, conocimientos, costumbres, usos, espacios, instituciones; se apropian también, sin necesariamente creer en ellas o consentirlas, de las reglas del juego necesarias para sobrevivir.

No nos proponemos dar cuenta de la apropiación en su dimensión interna, constructiva, de aprendizaje individual, aunque sabemos que está en el fondo de la realidad que observamos. Nos interesa relevar su consecuencia social, destacar los contenidos y las relaciones sociales específicas que están en juego en este proceso. El encuentro entre la apropiación sostenida desde abajo (desde alumnos, padres y maestros dé base) y el control ejercido desde los ámbitos de la burocracia estatal (en los que a su vez determinados sujetos dan existencia material a los mecanismos y las sanciones legitimadas por la legalidad institucional), muestra el sentido y la fuerza de propuestas alternativas de constitución de la escuela.

Al regresar, de esta reflexión acerca de los procesos, a los indicios registrados y los fragmentos significativos de la riqueza cotidiana de la escuela, nos encontramos con el problema de establecer diferentes niveles analíticos de los procesos pertinentes a la escala de realidad escolar elegida. Las categorías teóricas que designan los procesos constitutivos de la escuela, atraviesan en un mayor nivel de abstracción a las categorías sociales que marcan distinciones entre los espacios, los momentos, las funciones y los sujetos de la "institución" escolar. Permiten también reordenar con otro sentido, la desagregación de la escuela que se da en las categorías y dicotomías oficiales (maestros, alumnos, padres, escuela-comunidad, sindicato-burocracia), y señalar discontinuidades donde la concepción "desde arriba" supone homogeneidad.

El recurso analítico principal es la descripción, la reconstrucción de tramas a partir de evidencia diversa, o del desarrollo concreto de eventos, (construcciones, asambleas, festejos, clases), de pequeñas historias escolares en que se negocian y se construyen diferentes aspectos de la realidad escolar, en las que sujetos particulares muestran repertorios de prácticas y saberes específicos. Como referentes teóricos de la descripción, los procesos sociales ordenan el sentido de esa reconstrucción; permiten relievar, matizar, e interpretar, desde un punto más general, los detalles del registro. La descripción de una asamblea escolar o sindical por ejemplo, es posible de muchas maneras; en ellas buscamos una reconstrucción que, además de agotar la posibilidad "indicativa" de todas las intervenciones registradas, provea caminos para leer en ellas procesos como la apropiación de "usos" específicos que modifican una determinación dada, o procesos de individuación que subyacen a un discurso gremial aparentemente colectivo.

En este tipo de trabajo analítico, que muestra procesos sociales específicos presentes en las realidades escolares particulares que observamos, intentamos vincular lo cotidiano y lo histórico.

No nos interesa, en este proceso investigativo, determinar la generalización empírica o representatividad de nuestras descripciones de las escuelas estudiadas, 0 de los 
procesos específicos que reconstruimos, ya que la relievancia de estos responde seguramente a características particulares del contexto de la investigación.

Sí nos importa, en cambio, la posibilidad de generalizar la construcción teórica que se elabora en el curso del análisis; de generar a partir de esta concepción de escuela y de este tipo de categorías, el conocimiento de escuelas en otros contextos, en los que los procesos predominantes pueden ser distintos. Consideramos que una perspectiva histórica y comparativa permitirá ampliar el repertorio conceptual de procesos y de categorías pertinentes a la escala de la vida escolar cotidiana, y a la historia particular de la escuela en América Latina.

La conceptualización de la construcción social de la escuela, la precisión de conceptos que apresen procesos históricos y faciliten el análisis de lo cotidiano, son generalizables en otro sentido. En el contexto de nuestra inserción en instituciones educativas, han modificado nuestra mirada hacia los problemas, han trastornado nuestros criterios evaluativos y nuestros propósitos indicativos. Buscamos la presencia de la historia en la institución, así como del Estado en sus formas más implícitas; buscamos las apropiaciones reales y potenciales que se dan "desde abajo", desde los sujetos particulares que viven cotidianamente la institución. Buscamos nuevas categorías y formas de intervención política y pedagógica. Estas son inquietudes que nos llevan a participar en la construcción social misma de lo escolar. 